The 16th Economic International Conference

New Challenges and Opportunities for the Economy 4.0, May 7-8th, 2020, Suceava, Romania

\title{
The Transition from Industry 4.0 to Industry 5.0. The 4Cs of the Global Economic Change
}

\author{
Alexandra Veronica UNGUREANU \\ https://doi.org/10.18662/lumproc/ncoe4.0.2020/07
}

How to cite: Ungureanu, A.V. (2020). The Transition from Industry 4.0 to Industry 5.0. The 4Cs of the Global Economic Change. In C. Nastase (vol. ed.), Lumen Proceedings: Vol. 13. 16th Economic International Conference NCOE 4.02020 (pp. 70-81). Iasi, Romania: LUMEN Publishing House.

https://doi.org/10.18662/lumproc/ncoe4.0.2020/07 


\title{
The Transition from Industry 4.0 to Industry 5.0. The $4 \mathrm{C}^{\mathrm{s}}$ of the Global Economic Change
}

\author{
Alexandra Veronica UNGUREANU1
}

\begin{abstract}
When it comes about the 21st-century economy, we admit that we are still accustomed to the usage of the economic models in order to create a sustainable development of the economy, disregarding the fact that industrialization constantly replaces them with redesigned ones, developed by artificial intelligence and algorithms, paradoxically creating both stability and instability, which is why we are at the confluence of two revolutions in the attempt to generate global balance. The Fourth Industrial Revolution, 4.0, based on strategies regarding the technical vision of the economy's future, and The Fifth Industrial Revolution, 5.0, the one of Personification, which announces a new paradigm whose keyword is coopetition. The collision of these two revolutions will produce changes capable of recognizing the worthiness of human capital. Forthwith, the society is built under the smart city concept, based on digitalization and algorithms, but with fewer implications from the emotional economy side, which is at the core of economic growth and development. Therefore, the purpose of this article is to bighlight the importance of the personified economics impact in the new world economics through the implementation of the 4C's rule: critical thinking, communication, collaboration, and creativity.
\end{abstract}

Keywords: critical thinking; communication; collaboration; competition; buman capital.

\footnotetext{
1 “Stefan cel Mare” University of Suceava, Romania, alexandra.ungureanu2016@gmail.com 


\section{Introduction}

Many economic theories are based on mathematics or physical patterns, aimed to generate fundamental laws regarding the discharge process of economic behavior. However, economics is an achievement that belongs to mankind, which is why it is dependent on the rational or irrational behavior of those who operate within, so the economics has more in common with fine sciences, such as psychology, sociology, and politics, but the essential difference between economics and other sciences is that the analyzed systems are flexible. Furthermore, economists can suggest how to develop or improve this approach, aside from describing or explaining the methodology of the economic circles.

The $21^{\text {st }}$ century is marked by constant changes in the financial and social lives of humankind. The stability concept of the global balance is gravitated by economic forces, BigData, algorithms, and the most important factor, the human capital, subject to the gradual destruction of its role in supporting the economy. The global decision making policy regarding the future of the economy is subordinate to artificial intelligence, but this does not mean that an ever-better understanding of this progress is acquired, because economics is not exclusively about automation, figures, statistics, and charts. Economics is the psychology of numbers, it is humanistic and its humanity is given by what is in the core - humans and their impact in the global economy.

In the last years, the global economy has been crossed by negative events, which led to an interest in acquiring knowledge about this area. It is vital to understand the principles by which our economy is governed, in order to understand how it influences our lives in all the spheres of influence.

\section{Theoretical Background}

Humanity faces unprecedented revolutions and change is the only constant that can provide balance. Today, society is focused on information accumulation rather than on the ability to interpret information in order to distinguish between what is important and what is not important and in particular, to combine several pieces of information in a global mental state [1]. Technical skills should be reduced and general skills should be focused on because it can influence the ability to cope with the constant change in society, which in the $21^{\text {st }}$ century is the result of the impact of the global economy on people who are an integral part of the society. 
In 21 Lessons for the $21^{\text {st }}$ Century, Prof. Yuval Noah Harari relates that fact that pedagogical experts in the United States of America claim that schools should start teaching the $4 \mathrm{C}^{\mathrm{s}}$ because the most important of all skills will be the ability to cope with change, to learn new things and keeping the mental balance in unusual situations. To bold on with the world of 2050, you will need to invent not only new ideas and products - above all, but you will also need to reinvent forever [2].

The world is under the changing pressure, and based on Prof. Yuval Noah Harari's belief, I consider that adapting the $4 \mathrm{C}^{\mathrm{s}}$ paradigm from the education system to the economic system, might provide a holistic vision of the global economy, supporting it sociologically by developing critical and realistic thinking. Regarding the above interpretation, I consider that the human capital educated in the spirit of the $4 C^{s}$ can convert into an economic elite that will support the development of the global economy.

\section{Argument of the paper}

Changes in all areas are taking place at a fast pace where global requirements are very different from those of the recent past, which is why a change and adaptation is needed for the new things that are happening. The growth and stability of the global economy depend on the capacity of adaptation systems in the world. In both developed and developing countries, technology makes these processes easier to implement, while seeking new skills to enhance competitiveness in a global market.

The foundation of 21 st-century competencies is the so-called $4 \mathrm{C}^{\mathrm{s}}$, which refers to the American initiative P21[3]. The $4 C^{s}$ are an ideology adapted from school management and represent 4 important visions: critical thinking, communication, collaboration, and creativity. This paradigm has also started to be adopted by contemporary economists who believe that the implementation of the $4 C^{s}$ can help shape social and economic progress[4].

Considering the fact that the present research involves a topic about the importance of human capital, in order to validate my hypothesis about the importance of the $4 \mathrm{C}^{\mathrm{s}}$, I have chosen triangulation as a qualitative research method, based on the sufficiency and adequacy of the data selected and analyzed according to the theoretical needs of research[5].

I hold my opinion about the fact that this method is the most appropriated one because qualitative research implies the discovery of depth information, understanding, and knowledge assessed by human criteria, this type of discoveries being extremely useful in the process of knowing the human nature and the understanding decision-making processes, which is why this data cannot be achieved through the quantitative methodology. 


\section{Arguments to support the thesis}

In the recent years, the current economy becomes a unique global story where technological disruptions are removing the potential impact of human capital, which is why it must be taken into consideration the fact that humanity is under the threat of a technological revolution that could remove billions of people out of the labour market, and the prospect of mass unemployment cannot be overlooked. Human capital ready to adapt and to cope with these changes provides a safety net for recognizing their importance in all areas. Digitization and automation have a limited capacity to cover processes that result in supporting the economy, with the final decision-making part being the human capital performing and educated in the spirit of the following $4 \mathrm{C}^{\mathrm{s}}$.

- Critical thinking

In the last centuries, we have been constrained to choose starting with insignificant things, extending to situations that might have an increased impact on our lives, such as financial resources, migration, or the right retirement system. We have access to a tremendous flow of information, so it is very difficult to make the right choice, and when it comes to the business environment or the large-scale economy, the phenomenon is much more serious [6].

Critical thinking in economics offers the opportunity to make an indepth analysis of all the elements of the global economy, emphasizing the important parts such as the direct impact on economic growth and at the same time, to diagnose the destructive factors. We are likely to make different choices, even if we are not fully convinced of it, being perhaps the victims of a good marketing campaign, even if the elements of the situations are part of a restrictive sector and we are aware that it will not add value to our lives. This circumstance is the opportunity to eliminate these biases using the right tools of critical thinking, ultimately making decisions based on useful and reliable information.

In economics, critical thinking develops the ability of the economists to focus in order to formulate relevant research hypotheses, so that from the beginning, these hypotheses can be significant and impactful, thus being closer to achieve accurate results transposed into practical applications and economic models, but not before the significant interpretation and validation.

The significant impact that critical thinking might have on the global economy are colossal, considering the long-term effects. Also, comparative analyzes are a tool of major importance because by comparison the outstanding results can be highlighted even if, occasionally, economists do 
not agree with these policies through the medium of more or less objective reasons. Critical thinking provides the tools for convincing results selection so that the outcome of economic methods and models can be promoted and implemented in order to produce a positive impact on economic growth and development, therefore the result of objective research is based on much more informed decisions.

At the same time, the implications of artificial intelligence, Big Data or IoT, have led to the formation of dataism [7], a term that has been used to describe the mindset or philosophy created by the emerging significance of Big Data. Even if it provides a good understanding of decision-making processes, it distorts the social image of participants in the economy, creating different and utopic types of society. Although it broadens our horizons and makes us aware of the extensive spectrum of options that we have, without critical thinking we will not be able to select the relevant information from global data, focusing on information that does not deliver impactful results.

For these reasons, I believe that promoting critical thinking in the economy is sovereignty in the hands of economists as well as for entrepreneurs because it is a tool that helps them to neglect the aggregation of irrelevant data, focusing on what is relevant and recognizing that access to information does not represent the monopoly of developing methods of growth and development of the economy.

- Communication

The global economy evolves into an increasing interconnection, with the future becoming more important than the present because of the exhaustive changes which are accelerating and multiplying constantly. This interconnection is endorsed by global communication, a defining element of human behavior. When it comes to the economy, the major implications of the communication process for individuals are relevant in the fact that any decision-making behavior is influenced both directly and indirectly by the information achieved in the communication processes.

When it comes to economics, communication has a binary role: mechanism of information distribution and behavioral influence. Regarding this aspect, we can admit that communication is the result of the appliance of specific instruments of the economic analysis, such as efficiency indicators through the medium of efforts and results [8].

Neglecting the standardized measurement tools of traditional communication in the economy and the real results of quantitative research, I consider that communication should be analyzed at the interhuman level, because of the impact it might have on the global economy. This qualitative analyze, should be driven in order to emphasize the connection between the 
of global human capital who have a role in the transmission of economic information and all the actors involved in the global economy.

Momentarily, we are at the inception of the personification revolution, where artificial intelligence will collaborate with human capital and we will witness the importance of communication, given the fact that global economic development is the result of the human's contribution assisted by $\mathrm{IA}$, not the reverse.

- Collaboration

The development perspective of the global economy is to endeavor together in order to use efficiently the variety of resources at our disposal, given that companies operate in an interdependence line, which is why collaboration is needed in order to create a healthy ecosystem.

Under the impact of digitalization, the 4.0 Industrial Revolution deliver mass opportunities for the global economy through the convergence of new technologies, where takes place an accurate synergy between human talent and intuition, whose results might be used with success to devise a longstanding global evolution vision.

At the same time, when we discuss collaboration, it is imperative to foreground one of the major constituents of the collaborating system, which is the idea of pooling resources in order to create a healthy business ecosystem and sustainable economic growth. Collaboration and transparent partnerships are essential to maximizing the benefits of the accumulation of the changes that are drawn toward societies all around the globe in the fourth industrial revolution [9].

Regarding what we have mentioned above, I consider that collaboration is the main factor for the survival of the business environment and straightforwardly of the global economy, and sooner or later, segments that will not be part of the collaborative ecosystem will be eliminated.

- Creativity

In the economic environment, creativity generates non-material values and ensures sustainable development centered on the human capital, because people are the ones who use their imagination with the aim to increase the significance of an idea that might add value to the global business ecosystem.

More specifically - new ideas, not money or technologies, are the source of economic success nowadays and, more importantly, the source of human capital satisfaction. A creative economy improves new production lines, services, and trading, innovating both social and financial environment.

An economy that has adopted creativity as a factor of development is one that will expand in haste, defined by dynamic income and diverse and also sustainable labor market. 
This pattern began to relate with all economic activities that depend on creativity in order to increase economic value, regardless of whether the result involves a cultural element or not. This is why I consider that the idea of a creative economy applies to any situation where creativity is the main source of value expansion and the main cause of a financial transaction.

There are several ways to approach a creative economy. We can use the same indicators as in other economic systems, for example, production, consumer expenditure, employment, and trade. Businesses also use assessments, value chains, price, or transactional data [10].

I consider that the concept of creativity is the defining element of the 21 st-century economy, playing an important role in the digitalization of the 4.0 revolution as well as in the transition to the 5.0 revolution.

The foundations of the nowadays creative economy are based on two main features: the nature of the workforce and, in particular, the relationship between human capital and their work. This first feature was settled in the first industrial revolution and focused on urbanization in the fourth one alongside BigData and knowledge, which is why I am convinced that it will contribute to the constant development of global systems and humanity will witness the following revolutions, the personification revolution being only the next but unquestionably not the final one.

\section{Arguments to argue the thesis}

As I mentioned in the paper's argument, the aim of my research is to highlight the importance and role of the human resource in supporting the economy in the age of digitalization, taking into account future labor market prospects as well as the necessary skills. According to the Employment and Social Development Report by the European Commission in 2019 [11], recent changes in production processes, new information, and communication technologies are forcing economies to rapidly restructure processes in order to face competition, processes which include human capital.

Organizations and markets are globally interconnected via the internet, while digital, robotic, and artificial intelligence technologies revolutionize production and consumption processes. New technologies create new markets and jobs, with the structure of the global economy in a rapid process of change. These changes benefit services, with increases in service sectors exceeding those in the production area. Digitalization supports the ICT sector, which is globally expanding. 
New technologies create new markets and jobs, while traditional jobs are in the process of extinction. However, a long-term trend toward increasing the use of human capital can be seen from two perspectives:

- companies choose to give up a number of employees and those selected to remain are enrolled in various training schemes to develop skills so as to increase labor productivity, thus increasing capital and labor investment by complementing each other, increasing workers' skills and well-being;

- companies replace the workforce with capital whenever technology is possible, and robots and computers are deemed to be able to perform their tasks more efficiently.

Experts' conclusions are that both perspectives will play an important role in the global labor market [12]. Even if greater use of digitalization will lead to job losses, an important role in removing human capital from the labor market will be the innovation potential of firms and government policies that can support research and innovation. Changes in the labor market also concern the form of employment or the way in which work is done. This increasingly means that we are meeting work on digital platforms, part-time working contracts that offer more flexibility to both employees and businesses.

Working conditions have also been positively affected by technology and digitalization, leading to an improvement in the labor market in terms of autonomy, flexibility, health, and safety. In the labor market, a new player is identified: digital work platforms. There is still no easy and complete definition of so-called working platforms. The new collaborative economy has been described as an interaction of business models where activities are facilitated by collaborative platforms that create an open market for the temporary use of goods or services [13].

These services are usually provided online by both professional and private providers. Such known platforms on the internet include services provided from home (e.g. via Twago, Upwork or Clickworker), mobility services (e.g. via Uber), or working at the person's home (ListMinut, Helpling, etc.) [14]. These companies, established over the last decade, have seen a sharp increase in recent years, alongside the diversification of services offered. Apart from the financial and real estate sector, there are significant increases in the professional, scientific, and research, technical (engineering) sectors, as the least digitalized sectors using highly skilled and educated labor. 


\section{Dismantling the arguments against}

The future of the labor market is a subject under constant debate, but despite the fact that the experts have different views on what will be, there is a consensus that human capital must be prepared for a changing and uncertain economic environment. Employers typically point to a significant difference in the skills and abilities they expect from employees and the benefits of automation.

Innovation has continually changed the economy, starting with the first Industrial Revolution, continuing with the fourth Industrial Revolution, where we are now, but which will not remain for long as we are heading toward the 5.0 revolution of Personification, in which the importance of the human resource will be taken into account.

Technological breakthroughs and global competitiveness create new types of jobs that support the economy, which we have not even imagined a decade before, thus prompting whole industries to reshape.

Elite human resources training programs are only transitional, far from a knowledge-based curriculum that assesses skills, currently centered on assessments where adaptability to specific tasks predominate without stimulating critical thinking, communication, creativity, and collaboration, that could add value.

Advances in technology and automation have exponential growth rates and benefit in terms of resource savings compared to a large number of employees. The multitude of factors influencing labor market developments requires thorough, comprehensive analyzes covering the many aspects of its functionality. Demographic developments, coupled with socio-economic trends indicating the transition to a knowledge economy, accompanied by the decline in traditional professions, require a detailed assessment and forecasting of labor market trends.

The role of human resources is clear in terms of their involvement in efficiency gains: People are the active resources of the organization, because their potential, experience and people's passion, initiatives and their development activities contribute to increasing organizational efficiency and effectiveness [15], having the ability to greatly enhance the effect of using other resources.

The vast majority of approaches to the issue of the role of human resources in achieving success relate to the economy and details all the resources involved in the economic process and their importance. Thus, the role of the human factor in making progress is becoming increasingly well known. It is human resources that have a decisive influence on the economic outcome. For this reason, all disciplines that aspire to investigate economic 
progress give a wider or narrower space to the human factor and their contribution to the results.

Starting from their role within the organization we can characterize human resources as a prerequisite for the existence of the production process (work - production factor) in a general manner, which can directly influence the level of performance. In the same sense, John W. Boudreau says while technical facilities, technological equipment, or financial capital are important, buman resources are particularly essential for the development of the economy [16].

The rapid evolution of the economic environment under the influence of constantly moving factors is driving rapid changes in economic theory. The latter seeks to take account of changes in the macro and microeconomic environment by theory on realities and trying to provide relevant solutions to problems that have arisen in practice. These solutions are identified by skilled and educated human resources, without which the global economy could not follow a steady process of sustainable development.

\section{Conclusions}

Although we are at the inception of the industrial revolution 4.0, the speed with which digitalization is changing the interface of the global economy requires elements of the 5.0 Industry Revolution, which will be a challenge, but not necessarily negative as long as the tasks are a kingdom in such a way that as much human capital as possible is not removed and that removed can be supported by financial support and medical insurance programs, while robots will be used for technical work, human work and decision-making.

Regardless the fact that at the moment researching process have not posed a suitable database of analyzes, theories, and statistics on the integration of the 4Cs rule and its impact on Industry 4.0, I apprehend it as an area where research is at the starting point and statistics will steadily change, given the high exposure to the industrial revolution, technological innovation, and artificial intelligence. This exposure is the initial phase of the 5.0 Revolution, the one of personification, which announces a new paradigm whose keyword is coopetition, focused on cooperation between man and artificial intelligence. Coopetition is a term belonging to Francisco Jaime Quesado, a specialist in innovation and competition, representing a combination of competition and cooperation between people and robots, which is the hallmarks of this new era. It was used at the Conference on Industry 5.0, organized by the Consultative Commission on Industrial Change of the 
European Economic and Social Committee (EESC) on 22 November 2019. By putting people back into industrial production, alongside collaborative robots, we will witness massive global development and increased welfare for all nations and reducing negative impacts.

\section{References}

[1] Harari YN. 21 lessons for the $21^{\text {st }}$ Century. First edition. Chapter 19: Education is the only constant. Iaşi: Polirom, 2018. Pagination: 354

[2] Harari YN. 21 lessons for the $21^{\text {st }}$ Century. First edition. Chapter 19: Education is the only constant. Iași: Polirom, 2018. Pagination: 364

[3] Bishop J. Partnership for the $21^{\text {st }}$ Century Skills. USA: Battele for Kids. 2018. 20 pages. Available from:

https://www.imls.gov/assets/1/AssetManager/Bishop\%20Pre-Con\%202.pdf

[4] Royal Government of Bhutan. The Report of the High-Level Meeting on Wellbeing and Happiness: Defining a New Economic Paradigm. New York: The Permanent Mission of the Kingdom of Bhutan to the United Nations. 2012. 166 pages. Available from: http://www.2apr.gov.bt/

[5] Becker HS. The Epistemology of Qualitative Research. R. Jessor, A. Colby, and R. Shweder [ed.], Essays on Ethnography and Human Development, University of Chicago Press, Chicago. 1996. 15 pages. Available from: http://citeseerx.ist.psu.edu/viewdoc/download?doi=10.1.1.394.7240\&rep=re p1\&type $=$ pdf

[6] Leyden DP. Critical Thinking in Economics. Kona Publishing and Media Group Higher Education Division Charlotte, North Carolina 2011. 158 pages.

Available from: http://www.escepticismo.es/libros/Critical-Thinking-inEconomics.pdf

[7] Harari YN. Homo Deus. First edition. Iaşi: Polirom, 2018. Chapter 11: Data Religion. Pagination: 388

[8] Egan B. Information Superhighways: The Economics of Advanced Public Communication Networks. Telecommunications Policy. Public Utility Research Center. University of Florida. 1993. 17 pages. Pagination: 17. Available from: https://pdfs.semanticscholar.org/d68b/944a0ff434c7cc5e5f38a8700960bf4c0 937.pdf

[9] Kriechel T, Bakkalbasi N. A Social Network Analysis of Research Collaboration in the Economics Community. Long Island University College of Information and Computer Science. Yale University, Connecticut USA. 2006 Pagination: 12. Available from: https://core.ac.uk/download/pdf/11879617.pdf

[10] Hervani A. Helms, M. Increasing Creativity in Economics: The Service Learning Project. Journal of Education for Business. 2010. Pagination 267274, DOI: $\underline{10.3200 / J O E B} \cdot 79 \cdot 5.267-274$ 
[11] European Commission Directorate-General for Employment, Social Affairs and Inclusion. Employment and Social Developments in Europe 2019 Sustainable growth for all: choices for the future of Social Europe Directorate. Luxembourg: Publications Office of the European Union. 2019. Pagination: 332. Available from: https://op.europa.eu/en/publication-detail/Lpublication/747fefa1-d085-11e9-b4bf-01aa75ed71a1/language-en

[12] Kaji J, Hurley B, Gangopadhyay S. Bhat R. Khan A. Leading the social enterprise: Reinvent with a human focus. Deloitte Global Human Capital Trends. Deloitte Insights. 2019. 122 pages. Available from: https://www2.deloitte.com/content/dam/Deloitte/cz/Documents/humancapital/cz-hc-trends-reinvent-with-human-focus.pdf

[13] Hatzopoulos V. The Collaborative Economy and the EU Law. Hart Publishing. Oxford and Portland. 2018. 249 pages.

[14] Dazzi, D. Gig Economy in Europe. Italian Labour Law e-Journal. Issue 2, Vol. 12. ISSN 1561-8048. 2019. 56 pages. Available from: https://illej.unibo.it/article/view/9925

[15] Amabile T. Khaire, M. Creativity and the Role of the Leader. Harvard Business Review. October 2008 Issue. Available from: https://hbr.org $/ 2008 / 10 /$ creativity-and-the-role-of-the-leader

[16] Boudreau JW. Utility Analysis: A New Perspective on Human Resource Management Decision Making. Cahrs Working Paper Series. Center for Advanced Human Resources Studies. 1987. 80 Pages. Available from: https://digitalcommons.ilr.cornell.edu/cgi/viewcontent.cgi?article $=1451 \& c o n$ $\underline{\text { text }=\text { cahrswp }}$ 